\title{
Budd-Chiari Syndrome: A Case Report of a Rare Presentation of COVID-19
}

Azhar A. Sh. Hassan ${ }^{1}$, Mujtaba E. Alsaleh ${ }^{2}$, Muntadher E. Alsaleh ${ }^{3}$, Fatimah A. Al Zaher ${ }^{4}$, Fatema A. Almajed ${ }^{2}$, Ahmed M. Alkhudhair ${ }^{2}$, Maram M. Alali ${ }^{5}$, Hassan A. Alzayer ${ }^{6}$, Areej J. Alolayan ${ }^{6}$

1. Family and Community Medicine, Imam Abdulrahman Bin Faisal University, Dammam, SAU 2. Internal Medicine, King Faisal University, Hofuf, SAU 3. Internal Medicine, King Fahad Hospital in Alhofuf, Hofuf, SAU 4. Internal Medicine, Jazan University, Jazan, SAU 5. Internal Medicine, Imam Abdulrahman Bin Faisal University, Dammam, SAU 6. Internal Medicine, Medical University of Warsaw, Warsaw, POL

Corresponding author: Hassan A. Alzayer, zayery_2@gmail.com

\begin{abstract}
Coronavirus Disease 2019 (COVID-19) predominantly involves the respiratory system and shows a wide range of severity. There is a growing body of evidence about the occurrence of thromboembolic events in COVID-19. Case Report: We report the case of a 48-year-old female patient who presented with suddenonset abdominal pain. Physical examination revealed ascites and tender hepatomegaly. Subsequently, abdominal computed tomography was performed which revealed thrombosis in the hepatic vein and inferior vena cava in keeping with Budd-Chiari Syndrome. The patient was started on low-molecular-weight heparin and supportive care. Clinical improvement was observed over the course of the treatment and the patient was discharged after 10 days from the presentation. Thromboembolic events could be the first manifestation of COVID-19. Early recognition of these complications is crucial for prompt management.
\end{abstract}

Review began $12 / 26 / 2020$ Review ended 01/03/2021 Published 01/07/2021

\section{๑) Copyright 2021}

Sh. Hassan et al. This is an open access article distributed under the terms of the Creative Commons Attribution License CC-BY 4.0., which permits unrestricted use, distribution, and reproduction in any medium, provided the original author and source are credited.
Categories: Internal Medicine, Infectious Disease, Hematology

Keywords: covid-19, covid coagulopathy, budd-chiari syndrome

\section{Introduction}

Coronavirus Disease 2019 (COVID-19) primarily involves the respiratory system and shows a wide spectrum of severity ranging from asymptomatic to acute respiratory distress syndrome. However, extra-pulmonary manifestations of COVID-19 are gaining attention. It is reported that up to one-third of patients with COVID-19 exhibit coagulopathy [1]. The spectrum of coagulopathy involves venous and arterial events [1, 2].

Budd-Chiari syndrome develops due to an obstruction in the hepatic venous outflow. It has an incidence rate of 2.0 per million population. We present the case of a middle-aged woman with COVID-19 who presented in a clinical picture of Budd-Chiari Syndrome [3]. To the best of our knowledge, this is the first report of a patient with COVID-19 who developed this complication.

\section{Case Presentation}

We report the case of a 48-year-old female patient who presented to the emergency department complaining of diffuse abdominal pain which had been ongoing for three days and which was associated with progressive abdominal distension. The pain started suddenly and was increasing in severity. She rated the severity as 8 out of 10 on presentation. The pain did not radiate and has no exacerbating or relieving factors. She also reported having a decreased appetite. She did not report a history of nausea/vomiting, fever, or change in bowel or urinary habits. All other systems reviewed were non-contributory. The past medical history is remarkable for long-standing hypertension that is well-controlled with amlodipine $5 \mathrm{mg}$ once a day. The patient was not on oral contraceptive pills or hormonal therapy. She had not undergone any abdominal surgeries. She did not smoke cigarettes and had no history of alcohol drinking.

On examination, the patient looked in distress. She was not pale or icteric. Her vital signs were as follows: pulse rate of $120 \mathrm{bpm}$, blood pressure of $130 / 84 \mathrm{mmHg}$, respiratory rate of $14 \mathrm{bpm}$, and a temperature of 37.1 ${ }^{\circ} \mathrm{C}$. Abdominal examination revealed a generalized tenderness without clinical signs of peritonitis. Mild ascites and enlarged tender liver were noted. Chest examination revealed scattered crackles.

Basic hematological investigation revealed a hemoglobin of $13.5 \mathrm{~g} / \mathrm{dL}$, a leucocyte of $8 \times 103 / \mathrm{mL}$, and a platelet count of $350,000 / \mathrm{mL}$. As per our institution policy, the patient underwent a polymerase chain reaction (PCR)-based nasopharyngeal swab testing for COVID-19 which revealed a positive result. There was a marked elevation in the liver enzymes, including alanine transferase (1325 U/L), aspartate transferase (1344 U/L), alkaline phosphatase (605 U/L), total bilirubin $(2.1 \mathrm{mg} / \mathrm{dL})$, and international normalized ratio (1.6). Subsequently, the viral hepatitis serology panel yielded negative results. 


\section{Cureus}

In light of the clinical and radiological findings, the patient underwent a chest X-ray which revealed a bilateral patchy opacification in keeping with mild COVID-19 pneumonia. Furthermore, contrast-enhanced abdominal computed tomography revealed filling defects in the inferior vena cava and hepatic vein and enlarged non-homogenous liver (Figure 1).
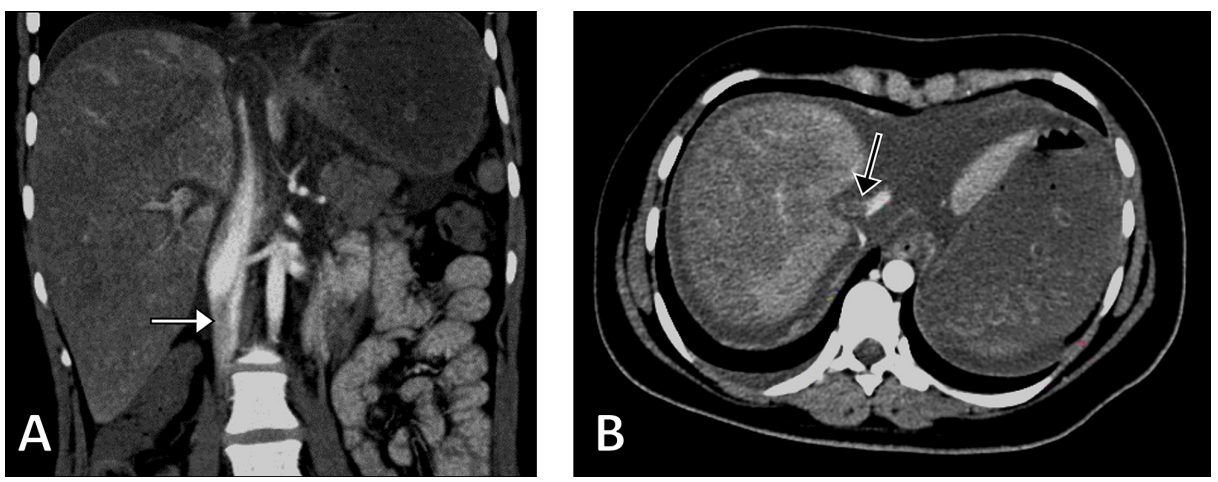

\section{FIGURE 1: Computed Tomography Images}

Coronal (A) and axial (B) computed tomography images demonstrating a filling defect in the inferior vena cava (white arrow) and the hepatic vein (black arrow).

Anticoagulant therapy with low molecular weight heparin $(1 \mathrm{mg} / \mathrm{kg} /$ day $)$ was immediately initiated along with supportive treatment, including diuretics. A comprehensive thrombophilia screen was performed and the results were negative. The patient demonstrated improvement in the clinical and laboratory parameters. She was discharged on oral warfarin after a hospital stay of 10 days. Results of repeated follow-up PCR tests for COVID-19 were negative. She was asymptomatic in the follow-up visit after one month from discharge.

\section{Discussion}

To our knowledge, this is the first case of a patient of COVID-19 presenting with Budd-Chiari Syndrome. There is a growing body of evidence about coagulopathy in COVID-19. While the pathogenesis remains not fully understood, hypercoagulation can be viewed in the context of Virchow's triad, which includes endothelial injury, stasis, and hypercoagulable state.

Several studies revealed changes in the level of coagulation factors in patients with COVID-19, such as elevated factor VIII and fibrinogen levels [4, 5]. Autopsy studies in patients who died from COVID-19 revealed significant generalized thrombotic microangiopathy [6].

The spectrum of coagulopathy in COVID-19 is wide and includes venous thromboembolism, arterial events, and microvascular thrombosis [7-9]. Evidence suggests that hemostasis dysregulation is more evident in patients with severe COVID-19 [7]. However, the present case demonstrated an example that coagulopathy may occur even in patients with mild COVID-19.

The guidelines for the management of coagulopathy in COVID-19 are not clear. In spite of patients being on optimal physician-directed anti-coagulant therapy, thrombotic events are known to occur [10].

\section{Conclusions}

Budd-Chiari syndrome should be borne in mind as a possible complication of COVID-19. Thromboembolic events could be the first manifestation of COVID-19. Early recognition of these complications is crucial for prompt management and better prognosis.

\section{Additional Information \\ Disclosures}

Human subjects: Consent was obtained by all participants in this study. Conflicts of interest: In compliance with the ICMJE uniform disclosure form, all authors declare the following: Payment/services info: All authors have declared that no financial support was received from any organization for the submitted work. Financial relationships: All authors have declared that they have no financial relationships at present or within the previous three years with any organizations that might have an interest in the submitted work. Other relationships: All authors have declared that there are no other relationships or activities that could appear to have influenced the submitted work. 


\section{Cureus}

\section{References}

1. Helms J, Tacquard C, Severac F, et al.: High risk of thrombosis in patients with severe SARS-CoV-2 infection: a multicenter prospective cohort study. Intensive Care Med. 2020, 46:1089-1098. 10.1007/s00134020-06062-x

2. Oxley TJ, Mocco J, Majidi S, et al.: Large-vessel stroke as a presenting feature of Covid-19 in the young . N Engl J Med. 2020, 382:60. 10.1056/NEJMc2009787

3. Ageno W, Dentali F, Pomero F, et al.: Incidence rates and case fatality rates of portal vein thrombosis and Budd-Chiari Syndrome. Thromb Haemost. 2017, 117:794-800. 10.1160/TH16-10-0781

4. Panigada M, Bottino N, Tagliabue $\mathrm{P}$, et al.: Hypercoagulability of COVID-19 patients in intensive care unit: a report of thromboelastography findings and other parameters of hemostasis. J Thromb Haemost. 2020, 18:1738-1742. 10.1111/jth.14850

5. Ranucci M, Ballotta A, Di Dedda U, et al.: The procoagulant pattern of patients with COVID-19 acute respiratory distress syndrome. J Thromb Haemost. 2020, 18:1747-1751. 10.1111/jth.14854

6. Menter T, Haslbauer JD, Nienhold R, et al.: Postmortem examination of COVID-19 patients reveals diffuse alveolar damage with severe capillary congestion and variegated findings in lungs and other organs suggesting vascular dysfunction. Histopathology. 2020, 77:198-209. 10.1111/his.14134

7. Bilaloglu S, Aphinyanaphongs Y, Jones S, Iturrate E, Hochman J, Berger IS: Thrombosis in hospitalized patients with COVID-19 in a New York City health system. JAMA. 2020, 324:799-801. 10.1001/jama.2020.13372

8. Bellosta R, Luzzani L, Natalini G, et al.: Acute limb ischemia in patients with COVID-19 pneumonia . I Vasc Surg. 2020, 72:1864-1872. 10.1016/j.jvs.2020.04.483

9. Magro C, Mulvey JJ, Berlin D, et al.: Complement associated microvascular injury and thrombosis in the pathogenesis of severe COVID-19 infection: A report of five cases. Transl Res. 2020, 220:1-13. 10.1016/j.trsl.2020.04.007

10. Haider MB, Abbas F, Hafeez W: A 46-year-old woman who presented with diabetic ketoacidosis and COVID19 pneumonia with multiple pulmonary thromboemboli: a case report. Am J Case Rep. 2020, 21:925794. 10.12659/AJCR.925794 